\title{
Modified Suction Cap Technique for Endoscopic Management of Esophageal Food Impaction
}

Acute food impaction, usually of a meat bolus, is the most common foreign body found in the esophagus [1]. Many methods of managing food impaction have been described. They include the administration of intravenous glucagon, the use of gas-forming carbonated beverages, of devices including nasogastric tubes and Foley catheters, and of endoscopy [1]. A particular endoscopic method described by Saeed et al. has proved to be a safe and effective means of retrieving food boluses [2]. We describe a simple and useful modification of this technique to improve the efficiency of endoscopic removal of impacted food.

As described by Saeed et al. a lubricated overtube is placed proximal to the meat after the meat bolus has been visualized. The endoscope is then removed. A drum tip (suction cap) is screwed into place on the tip of the gastroscope, converting the endoscope into a suctioning device with the ability to directly visualize the meat bolus. The endoscope is advanced through the overtube and under direct vision the endoscopist is able to suction the meat bolus into the drum and remove it safely [2].

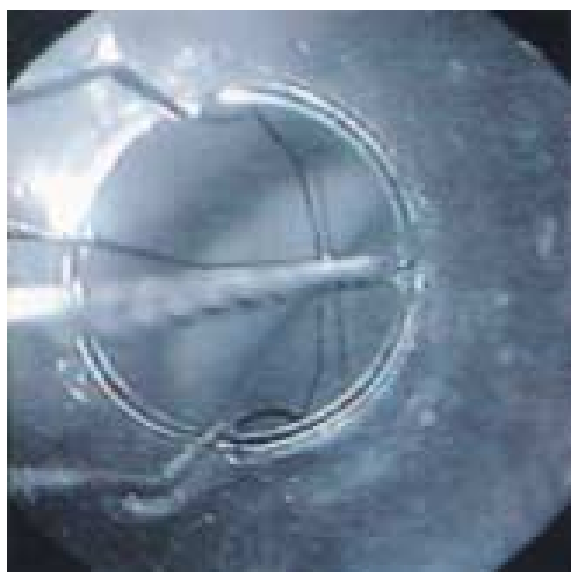

Figure 1 A Dormia basket is advanced through the drum tip and the meat bolus is grasped with the basket.
One drawback of this procedure which we have occasionally encountered is failure to keep the meat bolus secured by simply applying suction, despite using greater suction forces. This problem has occurred particularly when the meat has been partially digested. We have modified the Saeed procedure by advancing a Dormia basket into the endoscopic channel through the drum tip (Figure 1). The meat bolus is grasped with the basket, and the endoscope with the suction cup is slowly advanced towards the impaction while the Dormia basket grasping the bolus is carefully pulled toward the endoscope (Figure 2). Once the meat is inside the drum tip, full suction is applied and the impacted food is removed by means of this combination method.

This modification has proved to be successful in four cases, resulting in efficient removal of impacted meat. This technique may also reduce the time spent in removing food boluses by virtue of decreasing the number of passes required to clear the impaction. We conclude that the modified suction cap technique using a Dormia basket is a useful and effective maneuver for retrieving impacted food boluses.

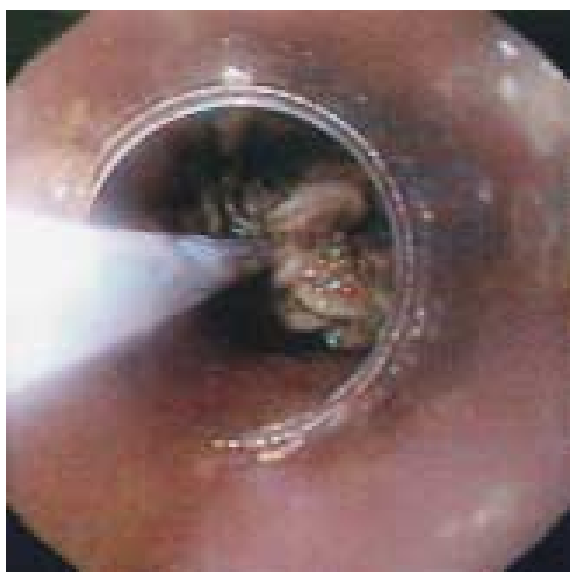

Figure 2 The meat bolus has been grasped with the basket. The endoscope with the suction cup is advanced towards the meat bolus impaction while the Dormia basket grasping the bolus is carefully pulled towards the endoscope.

\section{N. C. Patel, L. C. Fry, K. E. Mönkemüller}

Division of Gastroenterology,

University of Alabama at Birmingham, Birmingham, Alabama, USA

\section{References}

${ }^{1}$ Pouagare M, Brady PG. New techniques for the endoscopic removal of foreign bodies. Advanced therapeutic endoscopy. New York: Raven Press 1994; $2^{\text {nd }}$ ed: $154-174$

2 Saeed ZA, Michaletz PA, Feiner SD et al. A new endoscopic method for managing food impaction in the esophagus. Endoscopy 1990; 22: 226-228

\section{Corresponding Author}

\section{K. E. Mönkemüiller, M.D.}

Division of Gastroenterology University of Alabama at Birmingham 633 ZRB, UAB Station

Birmingham, AL 35924

USA

Fax: + 1-205-934-8493

E-mail: Monkemuller@aol.com 